Volume 8

Issue 4 - Cancer Screening

Article 7

10-18-2021

\title{
Integrating Patient-Reported Outcomes Into Clinical Genetic Testing for Familial Hypercholesterolemia
}

Rachele M. Hendricks-Sturrup

Robert Block

Christine Y. Lu

Follow this and additional works at: https://aah.org/jpcrr

Part of the Cardiology Commons, Cardiovascular Diseases Commons, Health Services Research

Commons, Medical Genetics Commons, Preventive Medicine Commons, Primary Care Commons, and the Psychology Commons

\section{Recommended Citation}

Hendricks-Sturrup RM, Block R, Lu CY. Integrating patient-reported outcomes into clinical genetic testing for familial hypercholesterolemia. J Patient Cent Res Rev. 2021;8:336-9. doi: 10.17294/2330-0698.1823

Published quarterly by Midwest-based health system Advocate Aurora Health and indexed in PubMed Central, the Journal of Patient-Centered Research and Reviews (JPCRR) is an open access, peer-reviewed medical journal focused on disseminating scholarly works devoted to improving patient-centered care practices, health outcomes, and the patient experience. 


\title{
Integrating Patient-Reported Outcomes Into Clinical Genetic Testing for Familial Hypercholesterolemia
}

\author{
Rachele M. Hendricks-Sturrup, DHSc, MA, ${ }^{1}$ Robert Block, MD, MPH, ${ }^{2,3}$ Christine Y. Lu, PhD ${ }^{1}$ \\ ${ }^{1}$ Department of Population Medicine, Harvard Pilgrim Health Care Institute and Harvard Medical School, Boston, MA; \\ ${ }^{2}$ Department of Public Health Sciences, University of Rochester Medical Center, Rochester, NY; ${ }^{3}$ Cardiology Division, \\ Department of Medicine, University of Rochester Medical Center, Rochester, NY
}

\begin{abstract}
Patient-reported outcomes (PROs) and PRO measures (PROMs) are often used to help clinicians and researchers understand patients' personal concerns, feelings, experiences, and perspectives following the implementation of an intervention. Notably, PROs and PROMs can inform health systems, health policy, and payers on the utility of clinical genetic testing based on each patient's personal values, perspectives, and potential health behaviors subsequent to testing. In this topic synopsis, we discuss the underexplored role of and implications for PROs and PROMs following genetic testing for familial hypercholesterolemia $(\mathrm{FH})$, an autosomal dominant genetic disorder of cholesterol metabolism that can lead to highly premature fatal and nonfatal myocardial infarction and stroke. We also discuss why the use and consideration of patient perspectives, via PROs and PROMs, are critical to the process of optimizing patient care across various $\mathrm{FH}$ treatment contexts. As expert clinician groups consider the latest evidence when establishing recommendations for $\mathrm{FH}$ genetic testing, there is a ripe opportunity for clinicians and researchers to explore the value and utility of PROs to inform and possibly improve care for patients diagnosed with FH. (J Patient Cent Res Rev. 2021;8:336-339.)
\end{abstract}

Keywords patient-reported outcomes; genetic testing; familial hypercholesterolemia; implementation science; cardiovascular disease

\section{Utility and Value of Patient-Reported Outcomes to Inform Clinical Care and Quality}

Patient-reported outcomes (PROs) and PRO measures (PROMs) can help clinicians and researchers understand and document patients' personal concerns, feelings, experiences, and perspectives regarding an intervention. Such data can also offer evidence to inform clinical guidelines, clinical research, insurance coverage policies and reimbursement decisions, health product development, health system policies and protocols, and standards of care. ${ }^{1-4}$ PROs are often context-driven and specific to disease, indication, and context, allowing PROs to precisely inform clinical practice. However, PROs following clinical genetic testing are not well defined or structured.

Dobrozsi and Panepinto proposed a conceptual framework to incorporate PROs as measures that define, from the patient perspective, patient symptoms and function, with the goal of tailoring patient therapies,

Corresponding author: Rachele M. Hendricks-Sturrup, Harvard Pilgrim Health Care Institute, Landmark Center, 401 Park Dr., \#401, Boston, MA 02215 (hendr@ohio.edu) improving patient outcomes, improving patient-provider communication, and improving health care provider quality and performance. ${ }^{5}$ This conceptual framework, as it applies to clinical genetic testing for various familial diseases, might be used to inform health systems, health policy, and payers on the utility of clinical genetic testing based on patients' personal values and perspectives as well as their health behaviors subsequent to testing.

One such intervention that is underexplored from a PRO standpoint is genetic testing for familial hypercholesterolemia (FH). $\mathrm{FH}$ is an autosomal dominant genetic disorder of cholesterol metabolism characterized by very high levels of low-density lipoprotein (LDL) cholesterol from birth, leading to highly premature fatal and nonfatal myocardial infarction and stroke. ${ }^{6}$ It affects an estimated 1 in 200 to 1 in 500 individuals, or 1.3 million people, in the United States; among those in whom a positive genetic test occurs, individuals with markedly elevated LDL cholesterol (ie, LDL-C of $>190$ ) have a significantly greater risk of mortality due to an adverse cardiovascular event. ${ }^{6,7}$

More than 1200 different mutations of LDL have been described and can be divided into 6 different classes, each affecting a particular aspect of LDL function. ${ }^{8}$ Classes 
include: synthesis of precursor LDL receptors; processing of LDL receptor in the Golgi body or endoplasmic reticulum; abnormal LDL binding; defective clathrinmediated endocytosis of LDL receptor; increased LDL receptor degradation (ie, increased proprotein convertase subtilisin/kexin type 9 [PCSK-9] activity); and inability of LDL receptor to attach to the cell's basolateral membrane. ${ }^{8}$ Another way to approach the LDL cholesterol metabolism concerns that occur in those with $\mathrm{FH}$ is to determine whether there is a defect in the LDL receptor or the complete absence of the LDL receptor, the latter of which presents with a more severe phenotype. ${ }^{8}$

In the United States, prevalence differs among races; for instance, the frequency of heterozygous $\mathrm{FH}$ is around 1 in 250 among White and Black individuals, whereas for Mexican American individuals and individuals of other races (collectively), it is around 1 in 414 and 1 in 343, respectively. ${ }^{7}$ Homozygous $\mathrm{FH}$ is far rarer, occurring around 1 in 1,000,000 people. ${ }^{9}$ Among certain geographic or ethnic populations, this frequency can be higher. For instance, in French Canadian individuals residing in Quebec, the estimated rate is around 1 in $275,000 .{ }^{10} \mathrm{In}$ addition to ethnic differences affecting the prevalence rate of $\mathrm{FH}$, gender and racial differences contribute to health disparities among groups of individuals with this genetic disease. ${ }^{11}$ For instance, being a female and/or of Asian or African descent is independently associated with a decreased likelihood of achieving LDL-C treatment goals, as compared to White patients. ${ }^{11}$ The Dutch Lipid Clinic Network (DLCN) and the Simon Broome Register (United Kingdom) diagnostic criteria for heterozygous FH both take into account family history, physical examination findings, and lipid profiles. ${ }^{6}$ These diagnostic criteria are not applicable to the pediatric population, and they may miss patients with only mild manifestations of heterozygous familial hyperlipidemia. ${ }^{6}$ Genetic tests, including gene panel testing and exome sequencing, can be conducted to look for variations in the LDL receptor, apolipoprotein $\mathrm{B}$, and $P C S K 9$ genes.

\section{PROs Pertaining to Opting for Familial Hypercholesterolemia Genetic Testing}

Statins have been available for many years and have effects in lowering cardiovascular disease event risk. ${ }^{12,13}$ Recommendations for lifestyle management include exercise, a diet low in saturated fat and cholesterol, and smoking cessation counseling. ${ }^{14}$ A $50 \%$ reduction in LDL-C is a minimum goal for all patients with $\mathrm{FH}^{6}{ }^{6}$ Pharmacological therapy includes statins, which are usually used in combination with ezetimibe, bile acid sequestrants, or PCSK9 protein inhibitors. ${ }^{6}$ Treatments for refractory cases in patients with the homozygous form of FH include lomitapide (inhibitor of microsomal triglyceride transfer protein large subunit) and mipomersen (antisense oligonucleotide that inhibits translation of apolipoprotein B messenger RNA). ${ }^{15}$ A twice-yearly injection of inclisiran, a small interfering RNA for PCSK9, was shown to have significant LDL-C reduction results in adults with heterozygous $\mathrm{FH}$ in a phase 3 clinical trial (ORION-10). ${ }^{16}$

The use and consideration of patient perspectives are critical to the process of optimizing patient care across these FH treatment contexts. ${ }^{6}$ In a previous publication, we reviewed the literature for studies that reported key clinical and nonclinical outcomes following FH genetic testing ${ }^{17}$ and found that reported PROs were described in two studies as "1) concerns about receiving genetic test results, and 2) out-of-pocket costs associated with FH genetic testing." 18,19 Our review also showed that the analysis and structure of PRO reporting across these two studies were vastly different.

Only 2 of 21 studies included in our literature review reported PROs, ${ }^{18,19}$ and only 1 of those 2 reported race/ ethnicity data (for which all 7 study participants were White). ${ }^{19}$ Pang et al qualitatively explored why some parents declined genetic testing for their children and identified the parent's concerns about possible stigmatization due to genetic testing, ${ }^{18}$ while Jones et al conducted interviews with 7 patients to understand the patients' overall experiences in receiving FH genetic test results. ${ }^{19}$ The study conducted by Jones et al was on behalf of Geisinger Health's MyCode Community Health Initiative, a pioneering study out of Pennsylvania that is 1) returning actionable results or secondary findings following whole exome sequencing of study participants, and 2) considering or collecting information about how participants cope with their results (eg, anxiety or distress) as well as participants' readiness to engage in recommended care. ${ }^{19,20}$

Aside from our published literature review, a case study revealed serious FH treatment limitations following reliance on the (U.S.) Make Early Diagnosis to Prevent Early Deaths (MEDPED), Simon Broome, or DLCN criteria alone or absent FH genetic testing or other emerging clinical criteria. ${ }^{21}$ Particularly, Mudgundi et al described a clinical case wherein a patient was diagnosed with possible $\mathrm{FH}$ after failing to meet Simon Broome, DLCN or MEDPED criteria, but rather by meeting the American Heart Association diagnosis recommendation. FH genetic testing was considered only after learning that a patient's insurer would deny coverage for a PCSK9 inhibitor unless the clinician provided to the insurer evidence of a causal FH genetic mutation. ${ }^{21}$ DeAngelis et al also showed 
similar patient concerns and perspectives, including the emotional impact of having $\mathrm{FH}$ and having interactions with insurance companies regarding coverage of $\mathrm{FH}$ treatments (ie, PCSK9 inhibitors) that may be predicated on positive $\mathrm{FH}$ genetic test results. ${ }^{22}$

\section{Proposed Targets for Future Research}

PROs following FH genetic testing are largely understudied and not well defined conceptually to inform patient management plans and decisions. As covered in the preceding sections, few studies have included both PROs and clinical outcomes following FH genetic testing, and PRO data collection methods and reporting are largely unstructured..$^{18,19}$ Increased and coordinated efforts among key stakeholders in the $\mathrm{FH}$ community are necessary to conduct more structured analyses of the patient/clinician experience with $\mathrm{FH}$ genetic testing. These are important to gain a deeper understanding about how and the extent to which patients with FH must navigate systemic, emotional, and other humanistic factors and barriers related to $\mathrm{FH}$ genetic testing and subsequent $\mathrm{FH}$ management and treatment in partnership with their caregivers. This is particularly true for racial-minority patients, who are at risk of being undiagnosed or underdiagnosed and who must navigate structural barriers, biases, and complexities among and across health systems globally to access clinical genetic testing, receive test results, and affordably engage in care management based on those results.

The American College of Cardiology recommends that genetic testing for $\mathrm{FH}$ should be offered to individuals of any age suspected of FH based on the examination of their clinical or family histories. ${ }^{23}$ Currently, there are important considerations surrounding this recommendation for FH genetic testing conducted within the United States and other similarly situated countries. First, the ratio of barriers to facilitators toward the clinical implementation of FH genetic testing in the United States is high. ${ }^{24}$ Second, FH is heavily underdiagnosed - especially among non-White populations in the United States ${ }^{17}$ - due to limited physician knowledge and experience with the disorder and unclear guidelines around the appropriate use of $\mathrm{FH}$ genetic testing for $\mathrm{FH}$ diagnosis. ${ }^{25}$ Third, FH is associated with premature heart disease, a disease that was the leading cause of death in the United States in 2017, rendering FH genetic testing a potential clinical diagnostic tool to help identify and confirm $\mathrm{FH}$ early or upon initial clinical suspicion. ${ }^{26}$

\section{Summary}

Based on the existing literature on patient-reported outcomes involving genetic testing of familial hypercholesterolemia, we recommend that clinicians and researchers: 1) understand the clinical limitations of relying on Simon-Broome, MEDPED, or DLCN criteria without confirmatory FH genetic testing; 2) identify existing contributing factors within their practices by determining the role $\mathrm{FH}$ genetic testing plays as either a barrier to or facilitator of effective FH management; and 3) identify, define or develop, and apply emerging PRO or PROM collection frameworks or concepts ${ }^{5,27}$ to methodologically collect patient perspectives that can offer robust insights into diverse patient journeys following $\mathrm{FH}$ genetic testing.

\section{Patient-Friendly Recap}

- Patient-reported outcomes (PROs) can be used to tailor care plans to individual preferences, though little is known about PROs pertaining to clinical genetic testing.

- Authors reviewed the literature on genetic testing for familial hypercholesterolemia (FH), a genetic disorder that can lead to deadly cardiovascular disease, to explore how various PROs within the scope of $\mathrm{FH}$ genetic testing might affect patient management.

- Clinicians should be aware that relying on standard $\mathrm{FH}$ diagnostic criteria without confirmatory genetic testing may hinder certain treatment coverage by insurers. Future research can apply emerging measures of PROs to study the diverse journeys traveled by individuals with $\mathrm{FH}$.

\section{Author Contributions}

Study design: all authors. Manuscript drafting: all authors. Critical revision: all authors.

\section{Conflicts of Interest}

Christine Lu reports a contractual arrangement with Massachusetts General Hospital's Center for Genomic Medicine that is unrelated to the work presented herein. Rachele Hendricks-Sturrup is presently employed by the Duke-Margolis Center for Health Policy.

\section{Funding Sources}

Christine Lu is supported in part by an Ebert Career Development Award at Harvard Pilgrim Health Care Institute and Harvard Medical School.

\section{References}

1. Anker SD, Agewall S, Borggrefe M, et al. The importance of patient-reported outcomes: a call for their comprehensive integration in cardiovascular clinical trials. Eur Heart J. 2014;35:2001-9. CrossRef

2. Squitieri L, Bozic KJ, Pusic AL. The role of patient-reported outcome measures in value-based payment reform. Value Health. 2017;20:834-6. CrossRef 
3. Flynn KE, Lin L, Ellis SJ, et al. Outcomes, health policy, and managed care: relationships between patient-reported outcome measures and clinical measures in outpatients with heart failure. Am Heart J. 2009;158(4 Suppl):S64-71. CrossRef

4. Trombley MJ, McClellan SR, Kahvecioglu DC, et al. Association of Medicare's Bundled Payments for Care Improvement initiative with patient-reported outcomes. Health Serv Res. 2019;54:793-804. CrossRef

5. Dobrozsi S, Panepinto J. Patient-reported outcomes in clinical practice. Hematology Am Soc Hematol Educ Program. 2015;2015:501-6. CrossRef

6. Gidding SS, Champagne MA, de Ferranti SD, et al. The agenda for familial hypercholesterolemia: a scientific statement from the American Heart Association. Circulation. 2015;132:2167-92. CrossRef

7. de Ferranti SD, Rodday AM, Mendelson MM, Wong JB, Leslie LK, Sheldrick RC. Prevalence of familial hypercholesterolemia in the 1999 to 2012 United States National Health and Nutrition Examination Surveys (NHANES). Circulation. 2016;133:1067-72. CrossRef

8. Leigh S, Futema M, Whittall R, et al. The UCL low-density lipoprotein receptor gene variant database: pathogenicity update. J Med Genet. 2017;54:217-23. CrossRef

9. Cuchel M, Bruckert E, Ginsberg HN, et al. Homozygous familial hypercholesterolaemia: new insights and guidance for clinicians to improve detection and clinical management. A position paper from the Consensus Panel on Familial Hypercholesterolaemia of the European Atherosclerosis Society. Eur Heart J. 2014;35:2146-57. CrossRef

10. Moorjani S, Roy M, Gagné C, et al. Homozygous familial hypercholesterolemia among French Canadians in Québec Province. Arteriosclerosis. 1989;9:211-6. CrossRef

11. Amrock SM, Duell PB, Knickelbine T, et al. Health disparities among adult patients with a phenotypic diagnosis of familial hypercholesterolemia in the CASCADE- $\mathrm{FH}^{\mathrm{TM}}$ patient registry. Atherosclerosis. 2017;267:19-26. CrossRef

12. Bays HE, Jones PH, Brown WV, Jacobson TA; National Lipid Association. National Lipid Association Annual Summary of Clinical Lipidology 2015. J Clin Lipidol. 2014;8(6 Suppl):S1-36. CrossRef

13. Whelton PK, Carey RM, Aronow WS, et al. $2017 \mathrm{ACC} /$ AHA/AAPA/ABC/ACPM/AGS/APhA/ASH/ASPC/NMA/ PCNA guideline for the prevention, detection, evaluation, and management of high blood pressure in adults: a report of the American College of Cardiology/American Heart Association Task Force on Clinical Practice Guidelines. Hypertension. 2018;71:e13-115. CrossRef

14. Defesche JC, Gidding SS, Harada-Shiba M, Hegele RA, Santos RD, Wierzbicki AS. Familial hypercholesterolaemia. Nat Rev Dis Primers. 2017;3:17093. CrossRef
15. Cupido AJ, Reeskamp LF, Kastelein JJP. Novel lipid modifying drugs to lower LDL cholesterol. Curr Opin Lipidol. 2017;28:367-73. CrossRef

16. Raal FJ, Kallend D, Ray KK, et al. Inclisiran for the treatment of heterozygous familial hypercholesterolemia. $N$ Engl J Med. 2020;382:1520-30. CrossRef

17. Hendricks-Sturrup RM, Clark-LoCascio J, Lu CY. A global review on the utility of genetic testing for familial hypercholesterolemia. J Pers Med. 2020;10(2):23. CrossRef

18. Pang J, Martin AC, Bates TR, et al. Parent-child genetic testing for familial hypercholesterolaemia in an Australian context. J Paediatr Child Health. 2018;54:741-7. CrossRef

19. Jones LK, Rahm AK, Manickam K, et al. Healthcare utilization and patients' perspectives after receiving a positive genetic test for familial hypercholesterolemia. Circ Genom Precis Med. 2018;11(8):e002146. CrossRef

20. Schwartz MLB, McCormick CZ, Lazzeri AL, et al. A model for genome-first care: returning secondary genomic findings to participants and their healthcare providers in a large research cohort. Am J Hum Genet. 2018;103:328-37. CrossRef

21. Mudgundi V, Williams G, Manou K, Block R. Genetic testing for a patient with suspected familial hypercholesterolaemia. BMJ Case Rep. 2018;2018:bcr2018225259. CrossRef

22. DeAngelis EJ, McIntosh S, Ahmed CD, Block RC. Familial hypercholesterolaemia patient-determined themes for community-engaged research. Health Educ J. 2018;77:293-302. CrossRef

23. Sturm AC, Knowles JW, Gidding SS, et al. Clinical genetic testing for familial hypercholesterolemia: JACC Scientific Expert Panel. J Am Coll Cardiol. 2018;72:662-80. CrossRef

24. Hendricks-Sturrup RM, Mazor KM, Sturm AC, Lu CY. Barriers and facilitators to genetic testing for familial hypercholesterolemia in the United States: a review. J Pers Med. 2019;9(3):32. CrossRef

25. Nordestgaard BG, Chapman MJ, Humphries SE, et al. Familial hypercholesterolaemia is underdiagnosed and undertreated in the general population: guidance for clinicians to prevent coronary heart disease: consensus statement of the European Atherosclerosis Society. Eur Heart J. 2013;34:3478-90. CrossRef

26. Centers for Disease Control and Prevention. Leading causes of death. Published February 7, 2020; accessed July 18, 2020. https://www.cdc.gov/nchs/fastats/leading-causes-of-death.htm

27. Deshpande PR, Rajan S, Sudeepthi BL, Abdul Nazir CP. Patient-reported outcomes: a new era in clinical research. Perspect Clin Res. 2011;2:137-44. CrossRef

(C) 2021 Advocate Aurora Health, Inc. 